\title{
Determination of the sea surface emissivity at L-band and application to SMOS salinity retrieval algorithms: Review of the contributions of the UPC-ICM
}

\author{
A. Camps, ${ }^{1}$ J. Font, ${ }^{2}$ M. Vall-llossera, ${ }^{1}$ I. Corbella, ${ }^{1}$ N. Duffo,${ }^{1}$ F. Torres, ${ }^{1}$ S. Blanch, ${ }^{1}$ \\ A. Aguasca, ${ }^{1}$ R. Villarino, ${ }^{1,3}$ C. Gabarró, ${ }^{2}$ L. Enrique, ${ }^{1,4}$ J. Miranda, ${ }^{1}$ R. Sabia, ${ }^{1}$ and \\ M. Talone $e^{1,2}$
}

Received 19 July 2007; revised 20 February 2008; accepted 11 April 2008; published 20 June 2008.

[1] This work describes the main effects that have to be taken into account to model the sea surface emission at L-band, and the existing approaches to perform the sea surface salinity retrieval from multiangular radiometric measurements. This manuscript reviews the activities carried out in these fields during the past years by the Universitat Politècnica de Catalunya (UPC) in collaboration with the Institut de Ciències del Mar (ICM - CSIC). They cover the precise measurement of the dielectric permittivity of the seawater at L-band, the sea surface emissivity (including the effect of wind-driven waves, swell, currents, rain, and oil spills), the comparison of experimental data with numerical models, and the development of sea surface salinity retrieval algorithms for SMOS using multiangular radiometric data. The first salinity retrievals using 2D aperture synthesis radiometry are also presented.

Citation: Camps, A., et al. (2008), Determination of the sea surface emissivity at L-band and application to SMOS salinity retrieval algorithms: Review of the contributions of the UPC-ICM, Radio Sci., 43, RS3008, doi:10.1029/2007RS003728.

\section{Introduction}

[2] The SMOS (Soil Moisture and Ocean Salinity) mission is an Earth Explorer Opportunity Mission from the European Space Agency that will be launched in 31 October 2008. Its goals are two-fold: to produce global and frequent maps of soil moisture and ocean salinity to improve the climate modeling [Kerr et al., 2001; Font et al., 2004]. SMOS' single payload is a new type of radiometer called MIRAS (Microwave Imaging Radiometer by Aperture Synthesis). MIRAS is a twodimensional synthetic aperture radiometer that operates at L-band (1400-1427 MHz), it has multiangular observation capabilities, and it can be operated in dual-polarization or full-polarimetric modes [Martín-Neira et al., 2002].

[3] The 1.400-1.427 MHz band is the lowest frequency band reserved for passive observations and offers the optimum conditions for sea surface salinity retrieval from space [Swift and McIntosh, 1983]. Despite this, the

\footnotetext{
${ }^{1}$ Universitat Politècnica de Catalunya, Barcelona, Spain.

${ }^{2}$ Institut de Ciències del Mar-CSIC, Barcelona, Spain.

${ }^{3}$ Universitat Autònoma de Barcelona, Cerdanyola del Vallès, Spain.

${ }^{4} \mathrm{ICFO}$ - Institut de Ciències Fotòniques, Castelldefels, Spain.
}

Copyright 2008 by the American Geophysical Union. 0048-6604/08/2007RS003728 sensitivity of the brightness temperature to the sea surface salinity is low, which makes this type of measurements very difficult. For example, at nadir the sensitivity is $0.5 \mathrm{~K} / \mathrm{psu}$ for a sea surface temperature of $20^{\circ} \mathrm{C}$, and decreases down to $0.25 \mathrm{~K} / \mathrm{psu}$ at $0^{\circ} \mathrm{C}$. Therefore, other variables that influence the brightness temperature signals such as the sea surface temperature, the sea surface roughness (wind-driven waves, swell, currents, rain, oil spills...) and the presence of foam must be properly accounted for in order to retrieve the sea surface salinity with the expected accuracy $(0.1 \mathrm{psu}$ over 1 month in $100 \mathrm{~km} \times 100 \mathrm{~km}$ to $200 \mathrm{~km} \times 200 \mathrm{~km}$ boxes, and 10-day resolution will be less accurate, but may be retained for certain operational applications) [Lagerloef, 2000; Koblinsky et al., 2003].

[4] In order to achieve such a stringent accuracy a number of experimental and modeling studies have been carried out in the past years to reduce the uncertainty in the different parameters involved in the modeling of the brightness temperature $\left(T_{B}\right)$ emitted by the sea surface [Camps et al., 2004a; Etcheto et al., 2004]:

$$
\begin{aligned}
T_{B, p}(\theta) & =(1-F) T_{B, \text { water }, p}(\theta)+F \cdot T_{B, \text { foam }, p}(\theta) \\
& =T_{B, \text { water }, p}(\theta)+F \cdot\left(T_{B, \text { foam }, p}(\theta)-T_{B, \text { water }, p}(\theta)\right) \\
& =T_{B, \text { water }, p}(\theta)+F \cdot \Delta T_{B, \text { foam }, p}(\theta),
\end{aligned}
$$




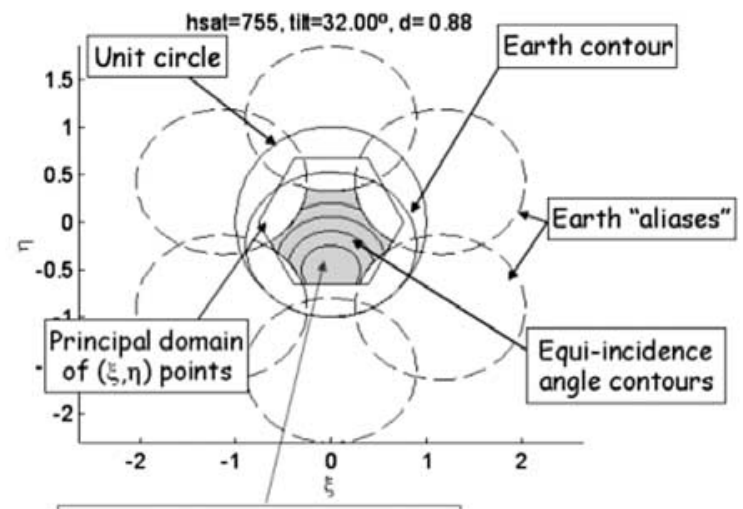

a) b)

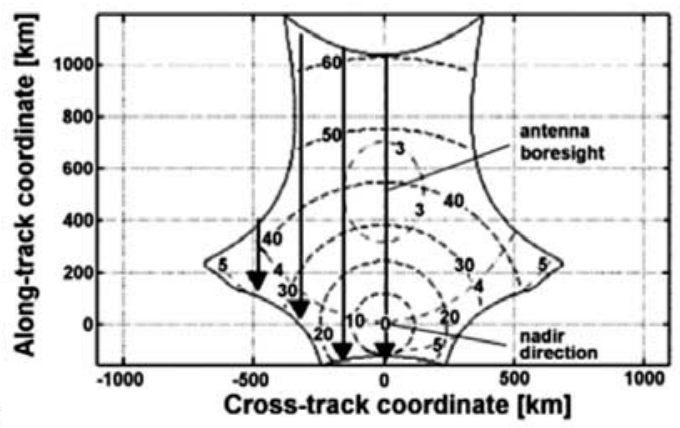

Figure 1. (a) SMOS observation geometry. Half space is mapped into the unit circle in $(\xi, \eta)$ coordinates. The alias-free Field Of View (FOV) imaged by the instrument (marked in gray) is enlarged up to the Earth "aliases" limit by taking into account the sky contribution. (b) Imaging of a pixel through the alias-free FOV under different incidence angles (from $0^{\circ}$ to $60^{\circ}$, dashed contours centered at nadir) and radiometric sensitivities (from $<3 \mathrm{~K}$ to $>5 \mathrm{~K}$, dash-dot lines centered at boresight). Parameters: 21 antennas per arm, $\mathrm{d}=0.875$ wavelengths antenna spacing, $\beta=32^{\circ}$ tilt angle, and $\mathrm{h}=$ $755 \mathrm{~km}$ platform height.

$$
\begin{aligned}
T_{B, \text { water }, p}(\theta)= & T_{B, \text { flat }, p}\left(\theta, \varepsilon_{r}(f, S S S, S S T)\right)+\sum_{n} \\
& \cdot \frac{\partial T_{B, \text { rough }, p\left(\theta, \text { param }_{n}\right)}}{\partial \text { param }_{n}} \cdot \operatorname{param}_{n} .
\end{aligned}
$$

[5] (The surface's brightness temperature $\left(T_{B}\right)$ accounts only for the surface's natural emission. The apparent brightness temperature $\left(T_{A P}\right)$ reaching the radiometer antenna includes atmospheric and ionospheric effects, and the downwelling cosmic, galactic, Sun... noises scattered over the surface.)

[6] The $T_{B}$ is related to the sea surface salinity through the dielectric constant $\left(\varepsilon_{r}\right)$ which also depends on the frequency $(f)$ and the temperature $(S S T)$. The impact of the surface roughness with respect to the flat sea $T_{B}\left(T_{B}\right.$, flat, $p$ ) is parameterized in terms of the $10 \mathrm{~m}$ height wind speed $\left(U_{10}[\mathrm{~m} / \mathrm{s}]\right)$ and/or the significant wave height $\left(H_{s}\right.$ [m]) and/or any appropriate descriptor ("param" in equation (1b)). The brightness temperature of the foam $\left(T_{B, \text { foam }, p}\right)$ is a function mainly of the polarization $(p)$, the foam thickness, the $S S T$ and the $S S S$, and the surface's foam coverage ( $F$ : from 0 to 1 ), which is mainly a function of $U_{10}$, but also of the SST and SSS (through the water viscosity) and the atmospheric instability [Monahan and Wolf, 1989].

[7] When dealing with the salinity retrieval problem, one must take into account the particular imaging characteristics of MIRAS. For the selected SMOS configuration the field of view is shown in Figure 1a in the $(\xi, \eta)$ director cosines domain, where the synthetic brightness temperature image is formed through a Fourier synthesis technique [Camps et al., 1997], and in Figure 1b in cross-track/along-track coordinates [Camps et al., 2005c].

[8] The arrows in Figure $1 \mathrm{~b}$ indicate the tracks followed by a pixel, since it enters in the field of view (top), until it leaves it (bottom). The number of snapshots in which the pixel will be imaged varies with the distance to the satellite ground-track. As this distance increases, pixels are imaged fewer times, the angular variation is reduced, and measurements become noisier, which translates into a degraded performance in terms of the quality of the retrieved parameters.

[9] Therefore, retrieval algorithms for SMOS shall be able to deal with a varying number of data points spanning over several incidence angles and noise levels as a function of the pixel being considered. In addition to random noise errors, the image reconstruction process induces other radiometric errors (radiometric accuracy and biases) that impact the SSS retrieval accuracy. Also, as one moves away from the E- and $\mathrm{H}$ - planes of the antennas, there is a geometric rotation of the reference frame that creates a polarization mixing between vertical and horizontal polarizations [Claassen and Fung, 1974]. In addition to this geometric rotation, there is a rotation of the polarization plane when an electromagnetic wave passes through the ionosphere (Faraday rotation). This rotation cannot be neglected at L-band: in most cases it produces an error in the brightness temperature below $0.1 \mathrm{~K}$, but in some cases, it may reach $1 \mathrm{~K}$ at large incidence angles [Yueh, 2000; Le Vine and Abraham, 2002; Waldteufel et al., 2004]. Although Faraday rotation estimates can be used, their accuracy is not enough for the required salinity accuracy, while in addition, local 


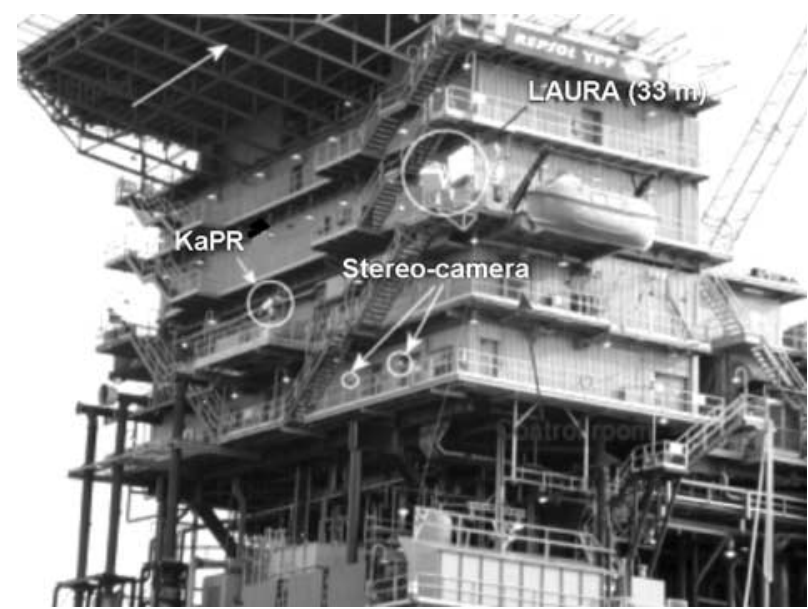

Figure 2. Instruments deployed at Casablanca oil rig (Mediterranean coast of Spain) for WISE 2000 and 2001.

ionospheric inhomogeneities can create different Faraday rotations within a pixel. A simple way to avoid this problem is to use the first Stokes parameter, which has the additional advantage (see section 2) of minimizing the angular variation of some other effects, which have opposite trend at vertical and horizontal polarizations, for example: the dielectric constant modeling errors, the wind speed and/or significant wave height dependence, the effect of currents and rain-induce roughness, the presence of foam [Camps et al., 2003].

[10] This manuscript reviews the different effects that affect the sea surface emissivity, including the contributions of the UPC and the ICM/CSIC in the field of sea surface salinity with special emphasis on ESA's SMOS mission. The present work is organized in two main parts: (1) Sea surface emission modeling and experimental results, describing the experiments and modeling results carried out to better understand the sea surface emissivity at L-band, and (2) sea surface salinity retrieval algorithms describing the current status of the salinity retrieval algorithms developed, including an external calibration using auxiliary data. The first salinity retrievals using $2 \mathrm{D}$ synthetic aperture radiometry data are also presented. Some of the results presented have already been published, but it is the first time they are presented in an organized manner showing the broad picture and the complexity of the problem faced.

\section{Sea Surface Emission Modeling and Experimental Results}

[11] The terms in the summation in equation (1b) represent the deviations of $T_{B}$ with respect to the flat sea brightness temperature $\left(T_{B, \text { flat, }}\right)$ due to the sea surface roughness. The WISE 2000 and 2001 (Wind and Salinity Experiment) experiments were carried out to quantify the impact of these terms. The UPC L-band AUtomatic RAdiometer (LAURA) was deployed at the REPSOL's Casablanca oil rig (Figure 2), 40 km offshore the coast of Tarragona (Spain), in conjunction with other oceanographic and meteorological instrumentation from the Institut de Ciències del Mar (Barcelona, Spain), the Universitat de València (València, Spain), the LODYC (now LOCEAN, Paris, France) and the CETP (Vélizy, France) [Camps et al., 2004a].

[12] The FROG 2003 (Foam, Rain, Oil spills and GPSreflections) experiment was performed at the IRTA facilities at Poble Nou del Delta (Tarragona, Spain) to specifically study the impact of foam, rain, and oil spills in the sea surface emissivity (Figures 3 and 4) [Camps et al., 2005b]. Over a flat water surface rain and oil have a negligible impact on the water surface $T_{B}$, but foam has to be included in the emission model at L-band.

[13] The $T_{B \text {, flat, }}$ term in equation (1b) is related to the sea surface salinity through the dielectric constant $\left(\varepsilon_{r}\right)$. However, discrepancies exist among different seawater dielectric constant models, and new accurate measurements were performed specifically at L-band.

\subsection{Influence of the Dielectric Constant}

[14] Several models for seawater permittivity exist in the literature. Until recently, the most widely used models in remote sensing have been the ones developed by Klein and Swift [1977] at L-band with $\mathrm{NaCl}$ solutions and by Ellison et al. [1998] and Mätzler [2006, chapter 5] from 3 to $90 \mathrm{GHz}$ with seawater. At L-band, both

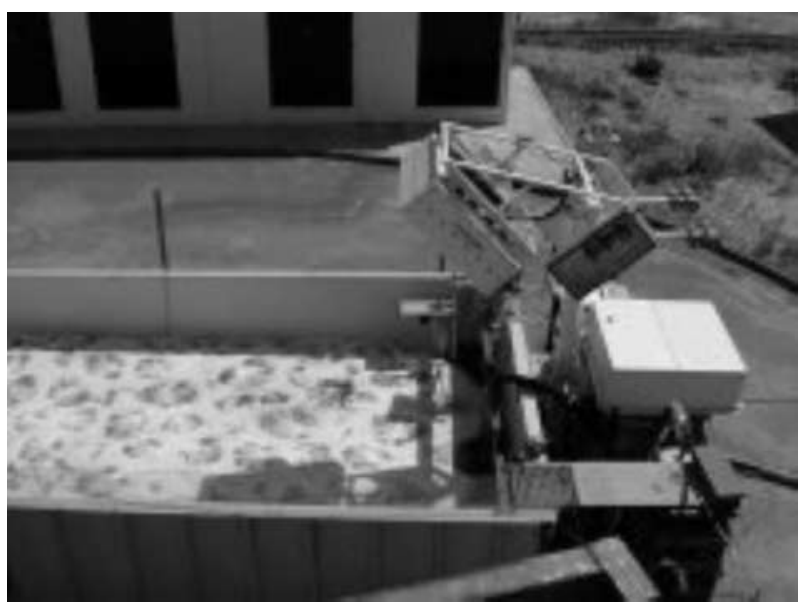

Figure 3. UPC LAURA radiometer deployed on one side of a $3 \times 7 \mathrm{~m}$ salty water pool with foam generator (FROG 2003). 


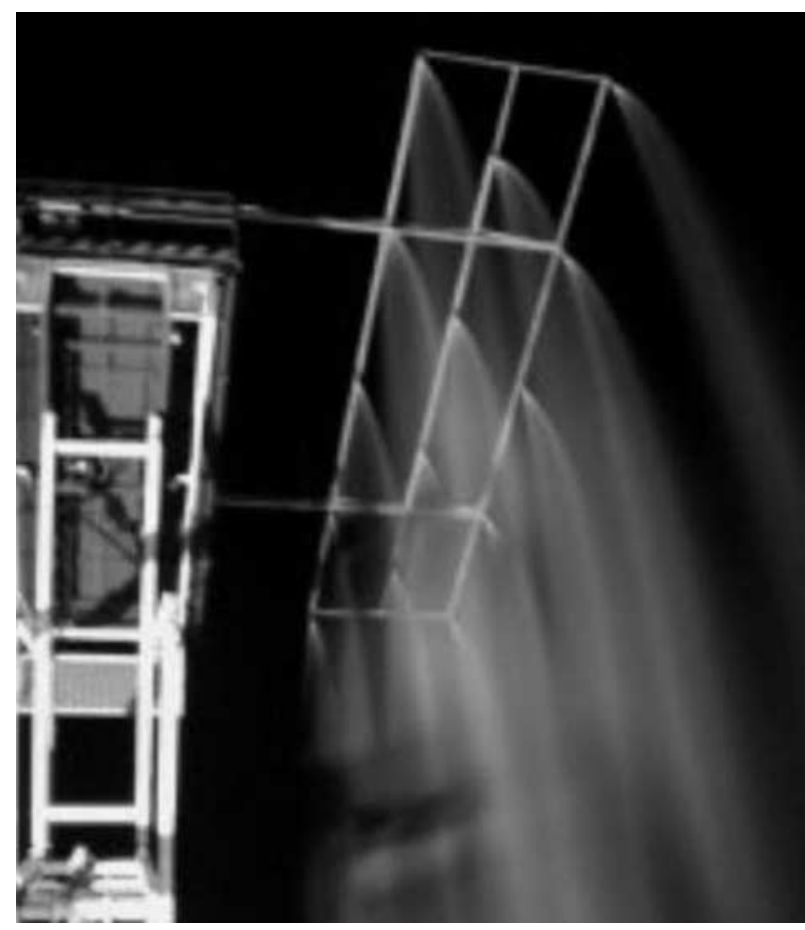

Figure 4. Rain generator over the salty pool with foam (FROG 2003).

models produce similar results, but the difference between $\varepsilon_{r}$ values is large enough to produce differences ranging from 0.4 to $1.1 \mathrm{~K}$ in the predicted $T_{B}$ [Camps et al., 2003; Dinnat et al., 2003]. Blanch and Aguasca [2004] performed specific measurements in the $1-2 \mathrm{GHz}$ range using a new technique based on the measurement of the scattering parameters (S-parameters) of an open stripline transmission line cell with seawater flowing between the two parallel plates of the cell. The measured variation of the dielectric constant at $1423 \mathrm{MHz}$ is shown in Figure 5a for distilled water and in Figure $5 \mathrm{~b}$ for 38 psu seawater vs. the physical temperature of the water sample. A series of measurements were repeated during 2006 to obtain an estimate of the repeatability of the measurements. For distilled water the standard deviation of the real and imaginary parts of the dielectric constant was found to be 0.09 and 0.008 , respectively. Due to the higher losses and reduced dynamic margin of the vector network analyzer, for 38 psu seawater the standard deviation of the real and imaginary parts of the dielectric constant are higher: 0.16 and 0.46 , respectively. These results compare better to the Klein and Swift [1977] model than to other existing models [Ellison et al., 1998; Mätzler, 2006; Wilson et al., 2004]. However, despite this improvement and after bias corrections, the rms difference between Wilson et al. measurements and the simulated $\mathrm{T}_{\mathrm{B}}$ using the Blanch and Aguasca [2004] model was $<0.16 \mathrm{~K}$ [Wilson et al., 2004], which is still too large for accurate salinity retrievals.

\subsection{Influence of Sea State}

\subsubsection{Sea Surface Roughness}

[15] The impact of the sea state on the L-band brightness temperature is small, but important enough to be one of the drivers of the SSS retrieval error budget. At frequencies much higher than L-band, sensors measure the short capillary waves that react faster to the wind speed than the long gravity waves, and the sea state is typically parameterized in terms of $U_{10}$. The ESA-sponsored field
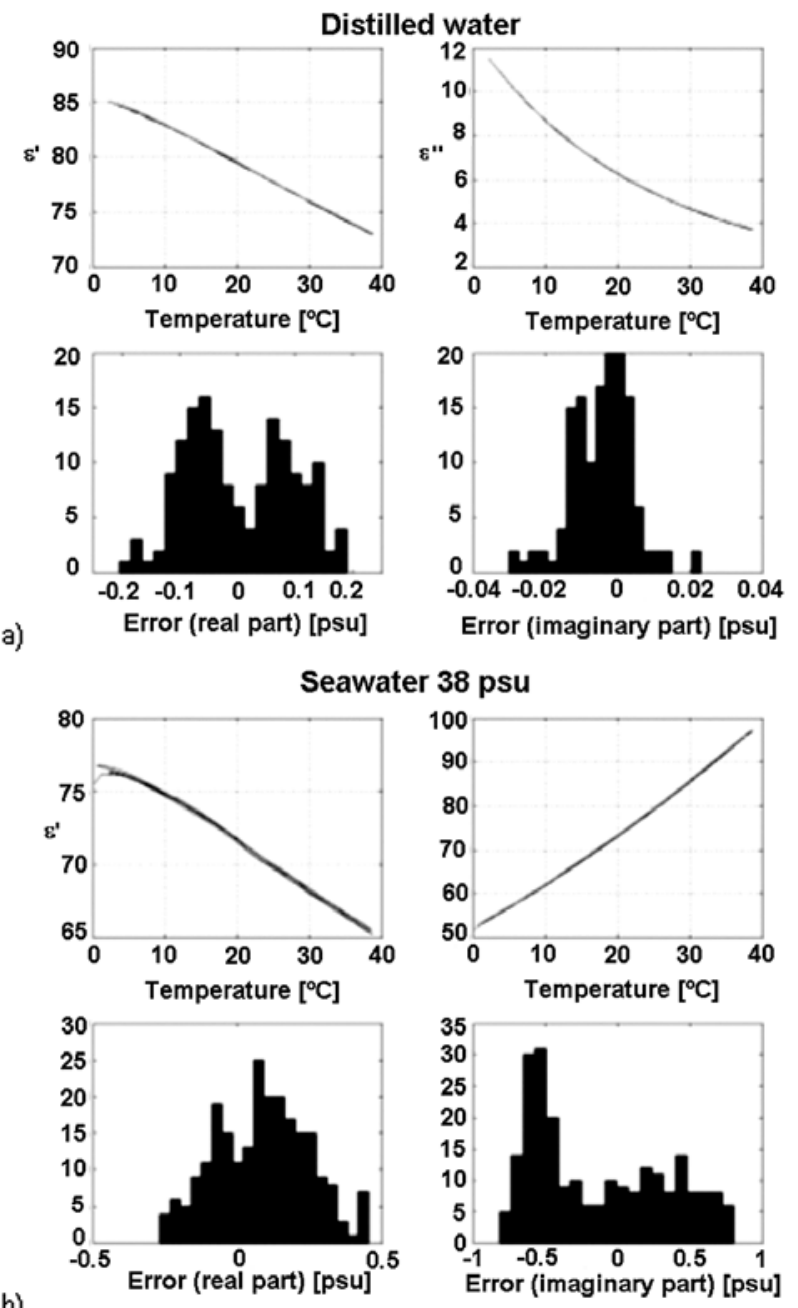

b)

Figure 5. Real and imaginary parts of the dielectric constant of (a) distilled water and (b) 38 psu seawater at $1.413 \mathrm{GHz}$ and associated error histograms. 

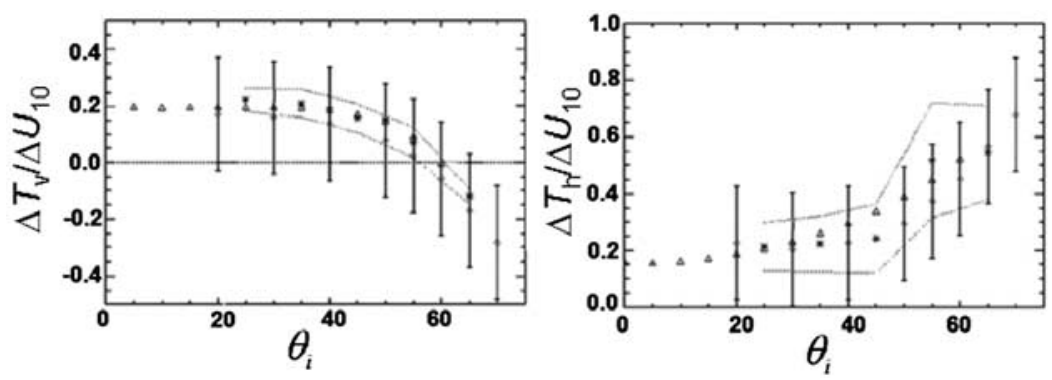

Figure 6. Intercomparison between the SSA (Small Slope Approximation: triangles) with Kudryavtsev sea surface spectrum (without foam), the WISE measurements (stars + dotted line for error bars) and Hollinger's measurements (diamonds + solid error bars) of the $\mathrm{T}_{\mathrm{B}}$ sensitivity to wind speed [Reul et al., 2006].

campaigns WISE 2000 and 2001 were designed to improve our understanding on the relationship between the brightness temperature changes and the wind speed. Long series of radiometric data were acquired at different incidence and azimuth angles in conjunction with atmospheric and oceanographic data.

[16] The intercomparison between Hollinger's and the WISE-derived brightness temperature sensitivities to $U_{10}$ and the numerically predicted ones using the Small Slope Approximation (SSA) method [Irisov, 1997; Reul and Chapron, 2001; Vall-llossera et al., 2003] and the Kudryavtsev et al. [1999] sea surface spectrum in shown in Figure 6. In deriving these sentitivities, $\Delta T_{B}$ was computed as the difference between the measured values and the flat sea surface model (equation (1)). $U_{10}$ was computed from the buoy and the oil rig meteorological stations values applying the atmospheric stability correction. Since the sensitivity of $T_{B}$ vs. $U_{10}$ is also a function of the wind speed (Figure 7), in order to make a homogeneous intercomparison between the experimental data and the numerical simulations (Figure 7), the different sensitivity values have to be weighted by the relative occurrence of wind speeds encountered during the field experiment. This is clearly seen in Figure 8, which shows the $\Delta T_{B}$ (deviation from the flat surface model) due to $U_{10}$ at $44^{\circ}$ incidence angle, derived from the measurements acquired when the radiometer was pointing to the East (WISE 2001). It is clearly appreciated that the sensitivity (slope) is higher at low wind speeds, and then remains constant above $U_{10} \sim 3-4 \mathrm{~m} / \mathrm{s}$ [Etcheto et al., 2004]. Recent results from the CoSMOSOS field experiments [Reul et al., 2007] indicate that there are two regimes at nadir $\left(U_{10}<7-8 \mathrm{~m} / \mathrm{s}\right.$ and $U_{10}>$ $7-8 \mathrm{~m} / \mathrm{s}$ ) and there are three different regimes at moderate incidences: for wind speed smaller than $6-7 \mathrm{~m} / \mathrm{s}$, a plateau region from $6-7$ to $8-9 \mathrm{~m} / \mathrm{s}$, and for wind speeds larger than $9-10 \mathrm{~m} / \mathrm{s}$.

[17] The large scattering in the measured data (Figure 8) seemed to indicate the possibility that other parameters in addition to $U_{10}$ (equation (1b)), such as the significant wave height $\left(H_{s}\right)$, are necessary to model it correctly [Gabarró et al., 2004a; Camps et al., 2004a]. More recently, the use of the sea surface mean square slope measured from GNSS signals of opportunity scattered
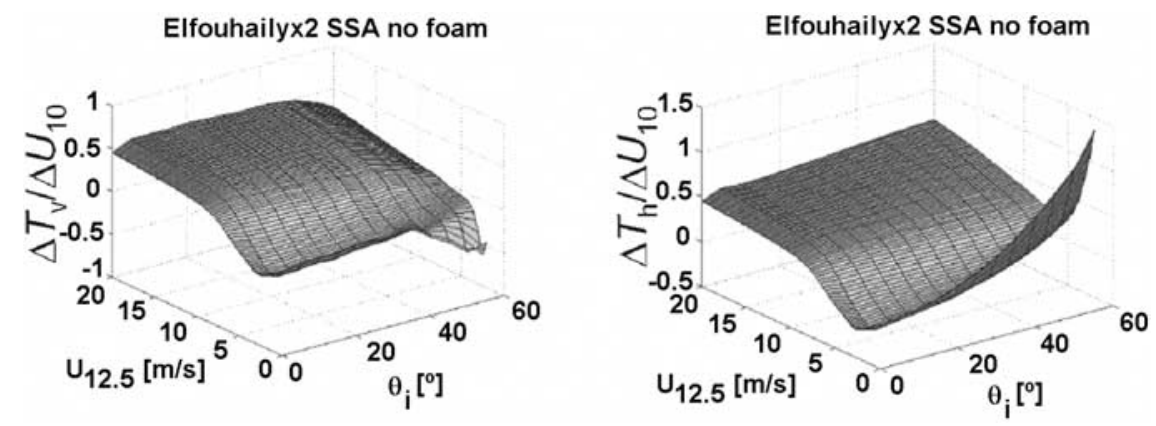

Figure 7. Brightness temperature sensitivity respect to $\mathrm{U}_{10}$ and $\theta_{\mathrm{i}}$ predicted by the SSA/SPM method for Elfouhaily et al. spectrum: (a) horizontal and (b) vertical polarizations [Vall-llossera et al., 2003]. 

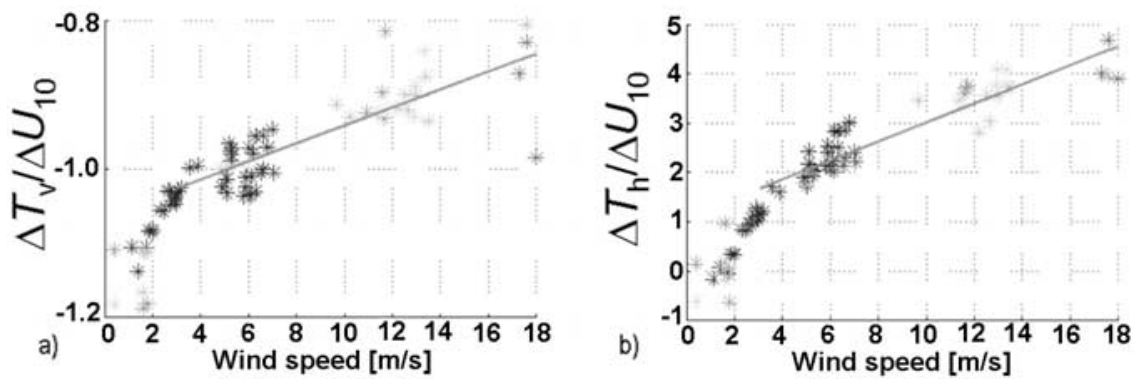

Figure 8. Wind speed dependence at (a) vertical, and (b) horizontal polarizations measured at $44^{\circ}$ incidence angle during WISE 2001 [Etcheto et al., 2004].

over the sea surface has also been studied to overcome the above mentioned uncertainties in $\Delta T_{B}$ with limited results [Sabia et al., 2007]. However, despite these multivariable regressions, the $T_{B}$ scattering still remains unacceptably high to achieve the salinity retrieval error goal. In addition to the instrument's inaccuracies and different calibrations, part of the scattering in the regressions may be due to the fact that a large part of the roughness that affect $T_{B}$ at L-band come from wavelengths different than $21 \mathrm{~cm}$. At small incidence angles there is nearly no influence of large waves to the $T_{B}$ with increasing wind speed. Nevertheless, at large incidence angles, both large and small scales effects are similar, and the horizontal polarization is more sensitive to the wind speed than the vertical polarization [Dinnat and Drinkwater, 2004]. Similar unexplained "fluctuations" of the brightness temperature at L-band $(\sim 0.5-1 \mathrm{~K})$ have been observed by other groups. D.M. LeVine (NASA Goddard) found oscillations in the $T_{B}$ data derived from ESTAR data at the Gulf stream, W. Wilson (JPL) found similar fluctuations in data from Monterrey bay (constant incidence angle and flying direction: constant corrections for the galactic noise), and N. Skou (TUD) found them in the LOSAC campaigns in the North Sea. Its origin remains unknown, but they could be originated by a kind of small-scale low-salinity "bubbles" or sudden changes in the roughness, originated by currents etc. that locally alter the sea surface roughness (section 2.2.5).

[18] Since an uncertainty in the brightness temperature of $\Delta T_{B} \approx 1 \mathrm{~K}$ translates into a $\Delta \mathrm{SSS}$ from 1.2 to $5 \mathrm{psu}$, depending on the polarization and incidence angle $\left(\Delta T_{B} /\right.$ $\Delta \mathrm{SSS}$ is $\sim 0.35-0.8 \mathrm{~K} / \mathrm{psu}$ at $\mathrm{V}$-pol, and $\sim 0.20-0.6 \mathrm{~K} / \mathrm{psu}$ at $\mathrm{H}$-pol) the accurate determination of the sea state influence on the brightness temperature remains one of the big challenges for the accurate salinity retrieval from space.

\subsubsection{Wind Direction Impact}

[19] The small azimuthal variations of the measured $T_{B}$ during WISE which are all within $0.5 \mathrm{~K}$ for $25^{\circ}$ to $55^{\circ}$ incidence angles at $\mathrm{V}$ - and $\mathrm{H}$-polarizations, can be attributed to differences between calibrations. However, an azimuthal scan performed during the most intense storm that happened in the past 25 years (Figure 9a) exhibit a very large azimuthal variation. In spite of the fact that the wind speed was moderately high $(11 \mathrm{~m} / \mathrm{s})$,

a)
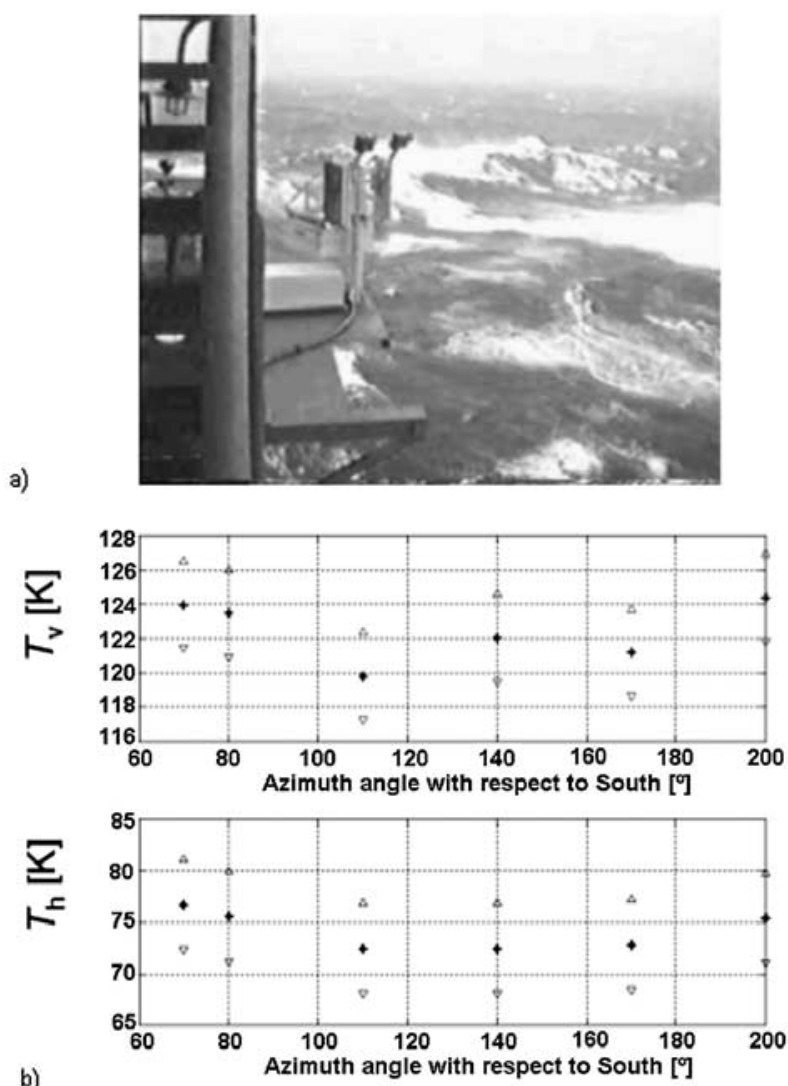

b)

Figure 9. (a) View of the UPC LAURA radiometer right after the control was lost $\left(\mathrm{U}_{70}>30 \mathrm{~m} / \mathrm{s}\right)$. (b) Sample azimuthal variations during one of the storms in WISE $2001\left(\theta_{\mathrm{i}}=45^{\circ}\right)$ : crosses $=$ mean values, triangles $= \pm 1 \sigma$ values. 

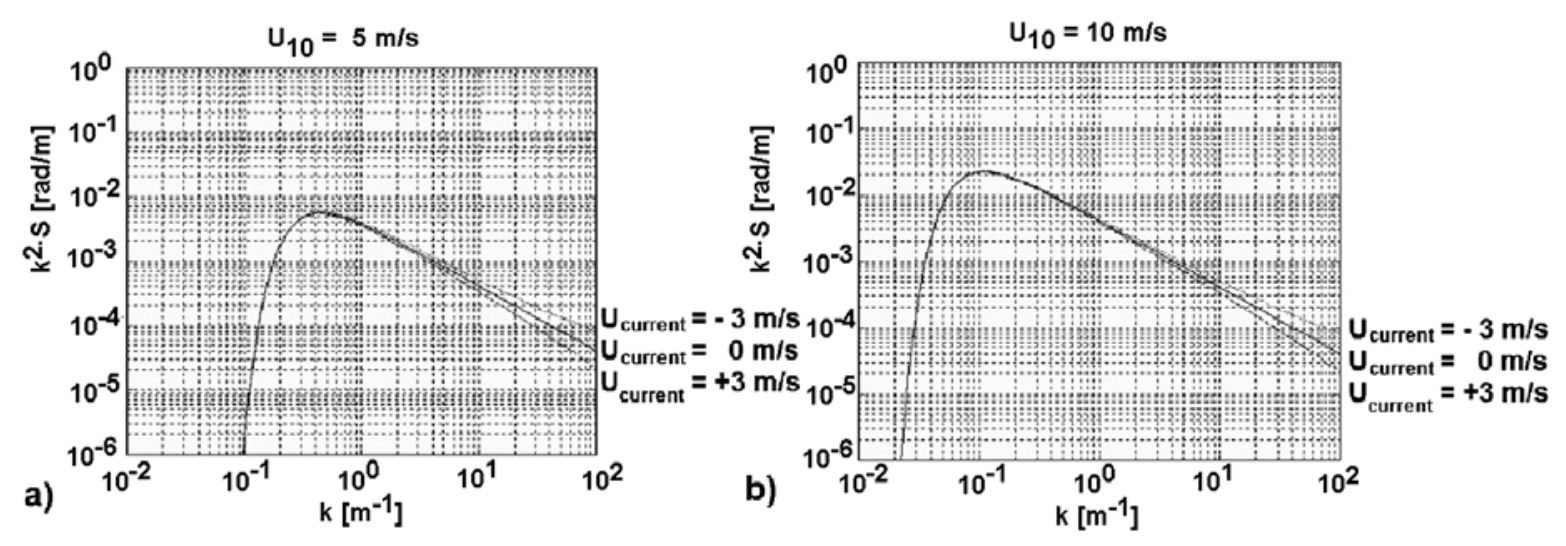

Figure 10. Sea surface slope spectra at (a) $U_{10}=5 \mathrm{~m} / \mathrm{s}$, and (b) $U_{10}=10 \mathrm{~m} / \mathrm{s}$, for $U_{\text {current }}=3 \mathrm{~m} / \mathrm{s}$ (dashed line), $\mathrm{U}_{\text {current }}=0 \mathrm{~m} / \mathrm{s}$ (solid line), and $\mathrm{U}_{\text {current }}=-3 \mathrm{~m} / \mathrm{s}$ (dotted line) [Camps et al., $2004 \mathrm{~b}$ ].

the waves were very large $\left(3 \mathrm{~m}<H_{s}<5 \mathrm{~m}\right)$, with very large crests that completely destroyed the $7 \mathrm{~m}$ deck of the oil rig, and seriously damaged the $13 \mathrm{~m}$ deck. In this case, the standard deviations were significantly higher (Figure 9b) than any numerical model prediction, which suggests that the wave asymmetry and the inhomogeneous distribution of foam may be dominant factors.

\subsubsection{Wave Development Impact}

[20] From the study of an extensive data set of developing sea states a dependence of the long-wave spectrum with the inverse-wave-age parameter $\Omega_{c}$ was obtained [Donelan et al., 1985; Dobson et al., 1989]. Seas are said to be fully developed, mature and young when $\Omega_{c}$ has values close to $0.84,1$ and $>2$, respectively. Differences between fully developed spectrum and nonfully developed spectrum can be important. Moreover in [Miranda et al., 2003b] several $U_{10}$ sequences recorded during WISE 2001 campaigns showed that $U_{10}$ was rarely constant and that large differences between the measured spectra and the fully developed spectra obtained with the measured local wind speed existed nearly in all cases. These differences between the actual spectrum and the corresponding fully developed one are responsible of differences of about a fraction of a Kelvin in the $T_{B}$ simulations at both polarizations [Miranda et al., 2003b]. These effects are important, but have an opposite trend at vertical and horizontal polarizations vs. incidence angle. Therefore, the impact in the sea surface salinity retrieval is minimized if the first Stokes parameter is used $\left(\mathrm{I}=T_{h}+T_{v}\right)$.

\subsubsection{Swell Effects Impact}

[21] Durden and Vesecky [1985] simulated a swell component by superimposing on the wind sea spectrum a Gaussian shaped swell spectrum, which is not usually coincident with the up-wind and cross-wind directions. Also, since the swell has a very directional behavior, the induced changes in the brightness temperatures have an azimuthal dependence as well, which is typically small $\left(\sim 0.02 \mathrm{~K}_{\text {peak }}\right.$ at moderate incidence angles and $<0.1 \mathrm{~K}$ at large incidence angles) [Miranda et al., 2003b]. The induced $T_{\mathrm{B}}$ changes have opposite trends at vertical and horizontal polarizations [Miranda et al., 2003b] which tend to compensate if the first Stokes parameter $\left(\mathrm{I}=T_{\mathrm{v}}+T_{\mathrm{h}}\right)$ is used in the sea surface salinity retrieval. 2.2.5. Effect of Currents

[22] Huang et al. [1972] derived a closed-form expression for the Kitaigorodskii-Pierson-Moskowitz sea surface height omnidirectional spectrum to include the effect of surface's currents. Sea surface currents impact the sea surface roughness spectrum (Figure 10), especially in the high wavenumber region, which in turn produces a change in the brightness temperatures (Figure 11) [Camps et al., 2004b]. Variations as large as $\sim 0.5 \mathrm{~K}$ are possible if strong currents occur in opposite direction of the wind, although they are usually much smaller.

\subsubsection{Effect of Rain}

[23] The effect of a rain cell within the antenna beam of a down-looking radiometer pointing to the sea surface is three-fold: (a) it increases the opacity of the atmosphere and the scattering of the up-welling radiation [Skou and Hoofman-Bang, 2005], (b) it creates a surface layer of fresh water, and (c) it changes the roughness of the sea surface [Craeye et al., 1997].

[24] The analysis of the perturbation of the sea surface caused by rain was performed in [Craeye et al., 1997], who created artificial rain with raindrop sizes ranging from 2 to $8 \mathrm{~mm}$, falling into a water tank from $13 \mathrm{~m}$ height. The omni-directional rain spectrum derived followed a log-Gaussian law. Figure 12a shows the Elfouhaily's wind-induced fully developed spectrum [Elfouhaily et al., 1997] for different wind speeds, and overlapped the rain-induced ring-waves log-Gaussian spectrum for different rain rates, concentrated on shortwave spectrum. The combined sea surface spectrum 


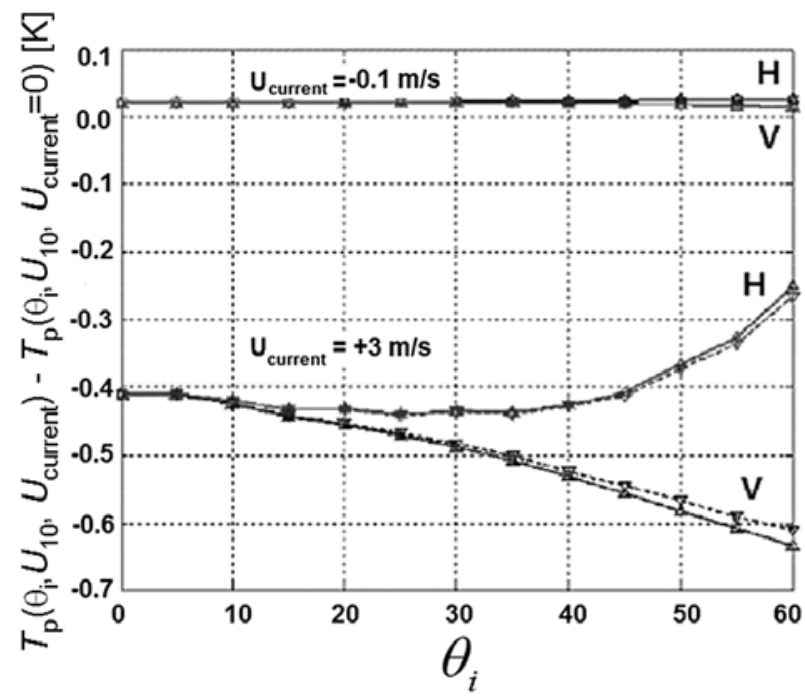

Figure 11. Brightness temperature change induced by a surface's current of $U_{\text {current }}=-0.1 \mathrm{~m} / \mathrm{s}$ (same direction as wind) and $\mathrm{U}_{\text {current }}=+3 \mathrm{~m} / \mathrm{s}$ (opposite direction as wind), for SSS $=35 \mathrm{psu}, \mathrm{SST}=15^{\circ} \mathrm{C}$, and $\mathrm{U}_{10}=5 \mathrm{~m} / \mathrm{s}$ (dashed line) and $\mathrm{U}_{10}=10 \mathrm{~m} / \mathrm{s}$ (solid line) [Camps et al., 2004b].

resulting from the nonlinear combination of the winddriven and rain-induced spectra can only be solved by an iterative process [Craeye et al., 1997]. The net effect of rain is an increment of the sea surface slopes variance (Figure 12b), which translates into a small brightness temperature increase.

[25] During the FROG campaign, measurements of the flat water surface emission of a fresh-water pond (Figure 4) were performed with and without rain and were com- pared to model results. The brightness temperature difference measured with the LAURA radiometer at both polarizations was very small, and extremely high "rain" intensities $(4000 \mathrm{~mm} / \mathrm{h})$ had to be generated to clearly detect the change in the fresh water surface's emissivity. At $1.4 \mathrm{GHz}$ and at a very high rain rates $(160 \mathrm{~mm} / \mathrm{h})$, the rain-induced $T_{B}$ change at nadir is estimated to be at most $\sim 0.075 \mathrm{~K}$, in agreement with numerical results computed with the Small Slope Approximation (SSA) method (Figure 13) [Miranda et al., 2003a]. However, it is likely that the effect over the sea will be different, since it is known that in addition to the creation of short waves, rain damps the long waves and it creates a pool of fresh water that may last several hours [Camps et al., 2004a].

\subsubsection{Effect of Oil Spills}

[26] The presence of oil spills impacts the $T_{B}$ measurements over the ocean in three ways: (a) it creates a thin layer that acts as an impedance matching layer between the water and the air, (b) it changes the polarization properties of the water molecules in the top layer [Blume et al., 1983], and (c) it damps the capillary waves reducing the surface's slopes variance [Cox and Munk, 1954].

[27] Radiometric measurements over oil spills at $1.43 \mathrm{GHz}$ have been reported by Blume et al. [1983], who reported brightness temperature increases between 2.5 and $3 \mathrm{~K}$ in agreement with a three-layer (water + oil + air) model for an oil thickness between 1.0 and $1.2 \mathrm{~cm}$. Very high brightness temperature depressions decreases, as large as $80 \mathrm{~K}$ in some cases, were also reported when the radiometer was flown over a monomolecular layer of oleyl alcohol due to the orientation of the water molecules. The brightness temperature decrease due to wave damping is small ( 2 K) [Webster et al., 1976].

$U_{10}=2,5,10,15,20 \mathrm{~m} / \mathrm{s} ; R R=2,10,50,100,250 \mathrm{~mm} / \mathrm{h}$
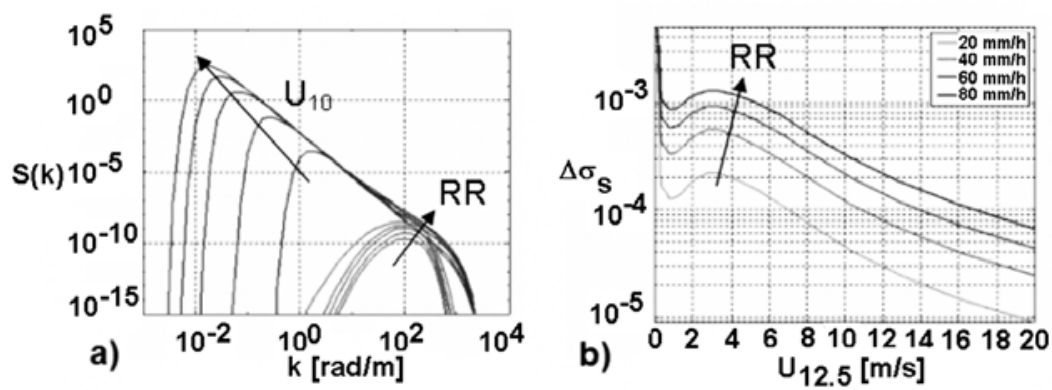

Figure 12. (a) Wind-induced spectrum $\mathrm{S}(\mathrm{k})$ for wind speeds $2,5,10,15$ and $20 \mathrm{~m} / \mathrm{s}$ and rain induced spectrum for rain rates 2, 10, 50, 100 and $250 \mathrm{~mm} / \mathrm{hr}$. (b) Slope standard deviation [no units] increment of sea surface roughness for rain rates of 20,40,60 and $80 \mathrm{~mm} / \mathrm{hr}$ respect to rain free conditions. 


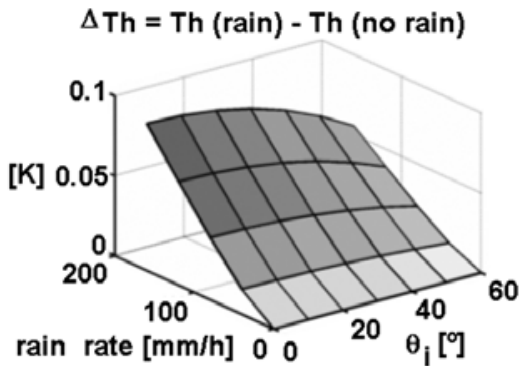

a)

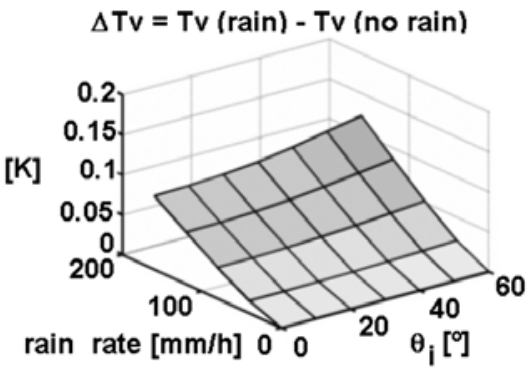

b)

Figure 13. $T_{B}$ change due to the presence of rain computed with SSA model (a) H-pol, and (b) V-pol [Miranda et al., 2003a].

[28] Taking into account that the thickness of oil slicks is actually small (tens of micron), during the FROG 2003 experiment, the $T_{B}$ change was measured for fresh and salt ( $37 \mathrm{psu})$ water when 0.5 and 1 liter of mineral oil $\left(\varepsilon_{r}=2.18+\mathrm{j} 0.01\right)$ were poured in the pond. For 1 liter of mineral oil, the thickness of the oil film was $48 \mu \mathrm{m}$ (larger than the thickness of naturally occurring oil films) and the effect on the brightness temperature was found to be negligible. Actually, numerical estimates predict a maximum brightness temperature increase of $0.005 \mathrm{~K}$ [Blume et al., 1983, Figure 7], which has a negligible impact in the sea surface salinity error.

\subsection{Influence of Foam}

[29] The emission of the foam layer was studied from WISE 2000 and 2001 (Figure 2) video imagery and during the FROG 2003 (Figure 3) field experiments. In FROG 2003 the emission of different foam layers generated by blowing different air fluxes was measured at horizontal and vertical polarizations, and from $25^{\circ}$ to $50^{\circ}$ incidence angle. Salinity ranged from 0 (freshwater) to $37 \mathrm{psu}$ (Mediterranean seawater). The measured water surface emissivity increase was in excellent agreement with a three-layer model [Camps et al., 2005b]. Figure 14 shows the measured normalized emissivity of foam vs. salinity and incidence angle, which increases with salinity, and increases/decreases at vertical/horizontal polarization with increasing incidence angle. The WISE-derived foam emissivities could be reproduced if the average foam thickness for open sea was assumed to be about $8 \mathrm{~mm}$.

\subsection{Brightness Temperature Semiempirical Model}

[30] With the previous information, the brightness temperature of the sea surface can be computed from the dielectric constant model and the sea surface temperature (which affects the $T_{\mathrm{B}}$, flat term in equation (1b)), and the different effects affecting the sea surface roughness (second term in right hand side of equation (1b)). The effect of foam is accounted for from Figure 14 (assuming an average foam thickness of $8 \mathrm{~mm}$ ) and using as foam cover fraction ( $F$ in equation (1a)) the expressions derived by Monahan and Lu [1990], Monahan and O'Muircheartaigh [1986], or Monahan and Wolf [1989], for example.
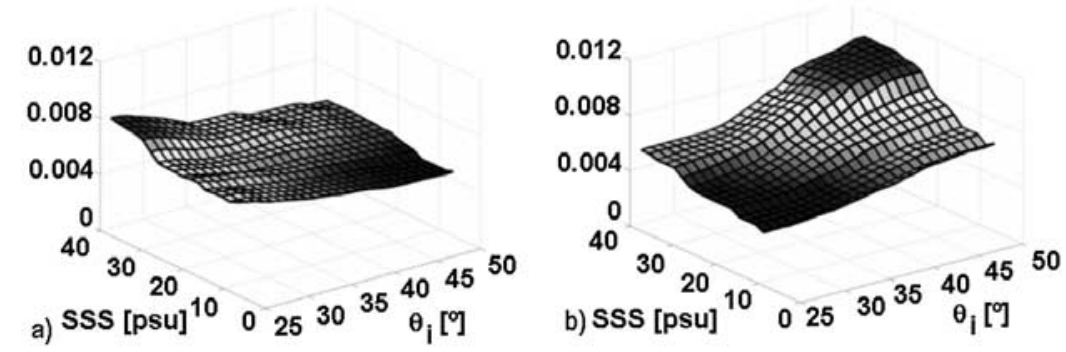

Figure 14. Water surface emissivity increase due to the presence of foam (per mm of foam thickness) $\left[\mathrm{mm}^{-1}\right]$ as a function of salinity and incidence angle: (a) horizontal, and (b) vertical polarizations [Camps et al., 2005b]. 
[31] In the SMOS Level 2 ocean salinity processor three models are included: the two-scale model (TSM), the Small Scale Approximation (SSA), and a semiempirical model based on the one previously described. In the semiempirical model, in addition to the dependence on $U_{10}$ and the significant wave height, additional parameters to account for the inverse wave age, the wind friction velocity, and the mean square slopes of the waves. These variables are assumed to depend linearly with the incidence angle in three different wind ranges: from 0 to $3 \mathrm{~m} / \mathrm{s}$, from 3 to $12 \mathrm{~m} / \mathrm{s}$ and for wind speeds larger than $12 \mathrm{~m} / \mathrm{s}$, and will be determined once SMOS data will be available [SMOS ATBD OS, 2005].

\section{Sea Salinity Retrieval Algorithms}

[32] Before applying the salinity retrieval algorithm, radiometric data have to be corrected for Faraday [Le Vine and Abraham, 2002; Waldteufel et al., 2004] and geometric [Claassen and Fung, 1974] rotations, as well as for atmospheric effects [Skou and Hoofman-Bang, 2005].

[33] Several inversion techniques have been developed and tested so far to retrieve the sea surface salinity from the future SMOS measured brightness temperature data. In these algorithms [SMOS ATBD OS, 2005], two main types of direct emissivity models are considered: empirical relationships (fit to experimental data), or approximate theory for sea surface emissivity (geometric optics, SSA, TSM...), as well as three main inversion techniques: analytical inversion [Reul and Chapron, 2003], iterative methods [Boutin et al., 2004; Camps et al., 2001, 2003, 2005a, 2005c; Gabarró et al., 2004b; Sabia et al., 2006] and neural network methods [Ammar et al., 2006].

[34] The nature of SMOS observations (varying number of observations for each pixel, with different levels of noise etc.) led to consider that the best suited algorithms are the iterative ones. These algorithms have been tested using real multiangular radiometric data acquired during WISE 2000 and 2001 field experiments [Gabarró et al., 2004b; Camps et al., 2004a] and with the SMOSillo ("little SMOS" in Spanish, also known as AMIRAS) [Duffo et al., 2007; First images from airborne version of SMOS, 2007] aboard the TKK Skyvan [Rautiainen et al., 2007], as well as with synthetic data simulated with the SMOS End-to-end Performance Simulator (SEPS) [Camps et al., 2005c].

\subsection{Simulation Studies}

[35] In order to test different sea surface salinity retrieval schemes an Ocean Salinity - Level 2 Prototype Processor was developed in the frame of the Spanish contribution to the SMOS project to be plugged in SEPS, including the external calibration [Camps et al., 2005a] and the retrieval of geophysical parameters. (External calibration is needed to compensate for brightness temperature and salinity retrieval biases.)

[36] The iterative algorithm minimizes a cost function of the form:

$$
\begin{aligned}
\varepsilon= & \frac{1}{N_{\text {obs }}} \sum_{n=1}^{\text {Nobs }}\left\{\left[\bar{F}_{\text {model }}\left(\theta_{n}, \hat{\bar{P}}\right)-\bar{F}_{\text {data }}\left(\theta_{n}, \bar{P}\right)\right]^{T} \cdot \overline{\bar{C}}^{-1}\right. \\
& \left.\cdot\left[\bar{F}_{\text {model }}\left(\theta_{n}, \hat{\bar{P}}\right)-\bar{F}_{\text {data }}\left(\theta_{n}, \bar{P}\right)\right]\right\} \\
& +\sum_{m=1}^{M} \frac{\left(P_{m}-P_{m, r e f}\right)^{2}}{\sigma_{P_{m}}^{2}}
\end{aligned}
$$

where:

[37] 1. $N_{o b s}$ is the number of measurements acquired at the same location in a satellite overpass, which depends on the distance to the satellite's ground track (Figure 1b).

[38] 2. $\bar{C}$ is the error covariance matrix that depends on the SMOS operation mode (dual or full-polarimetric [Martin-Neira et al., 2002]), the reference frame (Earth or antenna), and the pixel position in the field of view [Camps et al., 2005c].

[39] 3. $\bar{F}_{\text {model data }}$ is a vector that contains the modeled and measured observables $(\bar{P})$ at each incidence angle $\left(\theta_{\mathrm{n}}\right)$, and its structure depends on the formulation of the retrieval problem $\left(\bar{F}=\left[\bar{T}_{h}, \bar{T}_{v}\right]\right.$ in the Earth reference frame, $\bar{F}=\left[\bar{T}_{x}, \bar{T}_{y}\right]$ in the antenna reference frame, or $\bar{F}=\bar{I}=\bar{T}_{h}+\bar{T}_{v}=\bar{T}_{x}+\bar{T}_{y}$ if the first Stokes parameter is used).

[40] 4. The last summation in equation (2) accounts for the restrictions in the parameters $P_{m}$ (typically $M=3$ and $P_{m}$ are $S S S, S S T$ and $U_{10}$ ) around the reference values $P_{m, r e f}$ given by some auxiliary data sets, with a given variance $\sigma_{P_{n}}^{2}$. In the results presented, no restrictions are added to the $\operatorname{SSS}\left(\sigma_{S S S}^{2} \rightarrow \infty\right)$, since it was found that they forced the solution to converge to the reference value [Sabia et al., 2006].

[41] In equation (2), the term $1 / N_{o b s}$ is required to normalize the weight of the first term in the cost function and make it independent on $N_{o b s}$, which varies a lot with the pixel position within the swath $\left(N_{o b s, \max }=78\right)$.

[42] To minimize the impact of antenna cross-polar errors, and imperfect Faraday rotation correction (which may not be necessarily homogeneous over the SMOS pixel), it was first proposed [Camps et al., 2001] to use the first Stokes parameter $(I)$ computed in the antenna reference frame $\left(\bar{F}=\bar{I}=\bar{T}_{x}+\bar{T}_{y}\right)$ to retrieve sea surface salinity. This technique benefits from the higher radiometric sensitivity of the instrument in the dual-polarization mode, and presents just a small degradation (1.1-1.2) on the retrieval performance due to the smaller number of data (two measurements are added to get one: $\mathrm{I}=T_{x}+T_{y}$ ). 


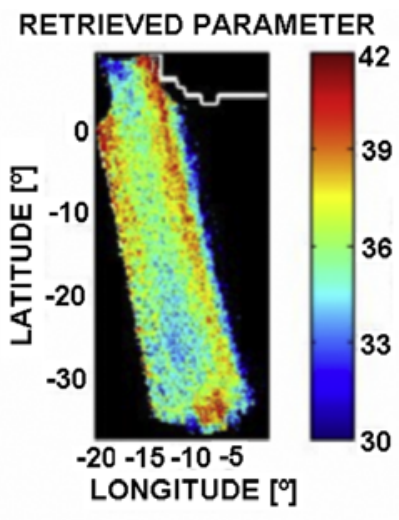

a)
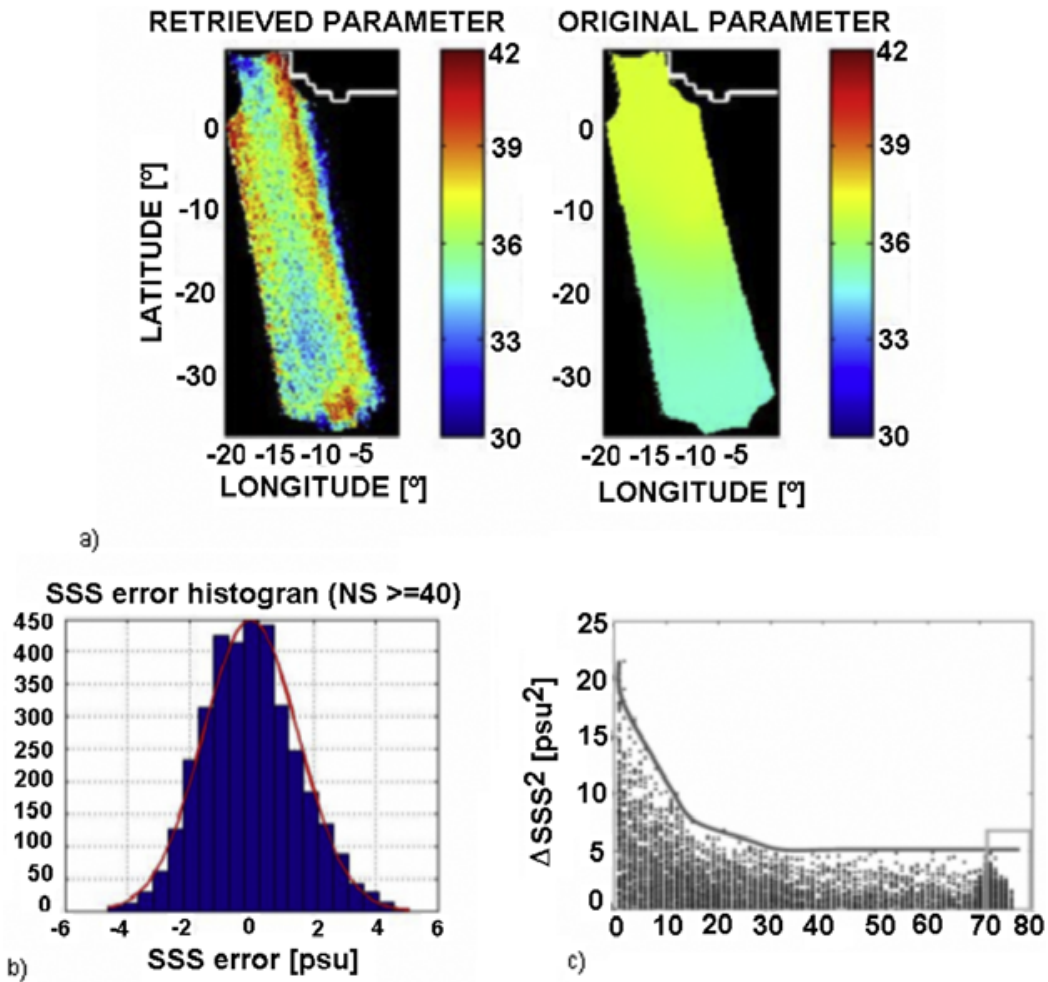

Figure 15. Simulated series of 180 consecutive snap-shots over the Southern Atlantic obtained with the SEPS (SMOS End-to-end Performance Simulator) corresponding to a 2 psu step (35 to $37 \mathrm{psu}$ ) over $10^{\circ}$ in latitude, $\mathrm{SST}=15^{\circ} \mathrm{C}$ and $\mathrm{U}_{10}=7.5 \mathrm{~m} / \mathrm{s}$, (a) retrieved and original sea surface salinity, (b) histogram of salinity retrieval errors (all pixels in alias-free field of view are included) mean $-0.02 \mathrm{psu}, \sigma=1.53 \mathrm{psu}$, and (c) salinity retrieval errors as a function of the number of observation of the pixel. Above 40 observation the salinity retrieval error stabilizes.

[43] The main conclusions of a recent study [Sabia et al., 2006] carried out to analyze the impact of the use of different auxiliary data sets on an ideal SMOS/MIRAS instrument just limited by thermal noise are:

[44] 1. In one overpass the rms SSS error is typically around $1 p s u$ increasing up to $4 p s u$ or more at swath edges.

[45] 2. Monthly temporally averaged retrieved SSS at pixel level provides a rms error about $0.33-0.55$ psu.

[46] 3. Spatio-temporally averaged retrieved SSS in a period of 30 days and in $1^{\circ} \times 1^{\circ}$ boxes, leads to rms retrieved SSS error between $0.055-0.309 \mathrm{psu}$, and in $2^{\circ} \times$ $2^{\circ}$ boxes between $0.032-0.291 \mathrm{psu}$.

[47] 4. The difference between the direct and inverse models (used to create the synthetic $T_{B}$ 's and in the SSS retrieval, respectively), is responsible of the introduction of a bias in the retrieved SSS, different models leading to different biases.

[48] 5. The instrument's radiometric noise does not play a crucial role, since its effect is mostly filtered out in the spatio-temporal averaging procedure.
[49] 6. Apart from the intrinsic auxiliary $U_{10}$ and SST difference with respect to the actual values; additional residual error sources lie in biased auxiliary wind field mean values and in strong zonal inhomogeneities between wind fields.

[50] Other studies [Camps et al., 2005a] have shown that, without auxiliary data and after spatio-temporal averaging ( 30 days, $\left.1^{\circ} \times 1^{\circ}\right)$ the SSS rms error ranges from $0.2 \mathrm{psu}$ at the equator to $0.7 \mathrm{psu}$ in polar regions.

[51] The OS L2 Prototype Processor includes an ARGO buoy data module to retrieve salinity values close to surface (depth $<10 \mathrm{~m}$ ) over a sliding window of 30 days around the satellite overpass. These data are kriged [Burgess and Webster, 1980] and used with other auxiliary data to model the sea surface $T_{\mathrm{B}}$ and cancel instrument and image reconstruction biases [Camps et $a l ., 2006]$ and the biases generated in the retrieval process due to errors in the dielectric constant model and the, for example, wind speed dependence [Sabia et al., 2006]. Figure 15 presents the results of a simulated SMOS overpass over the South Atlantic (180 consecu- 

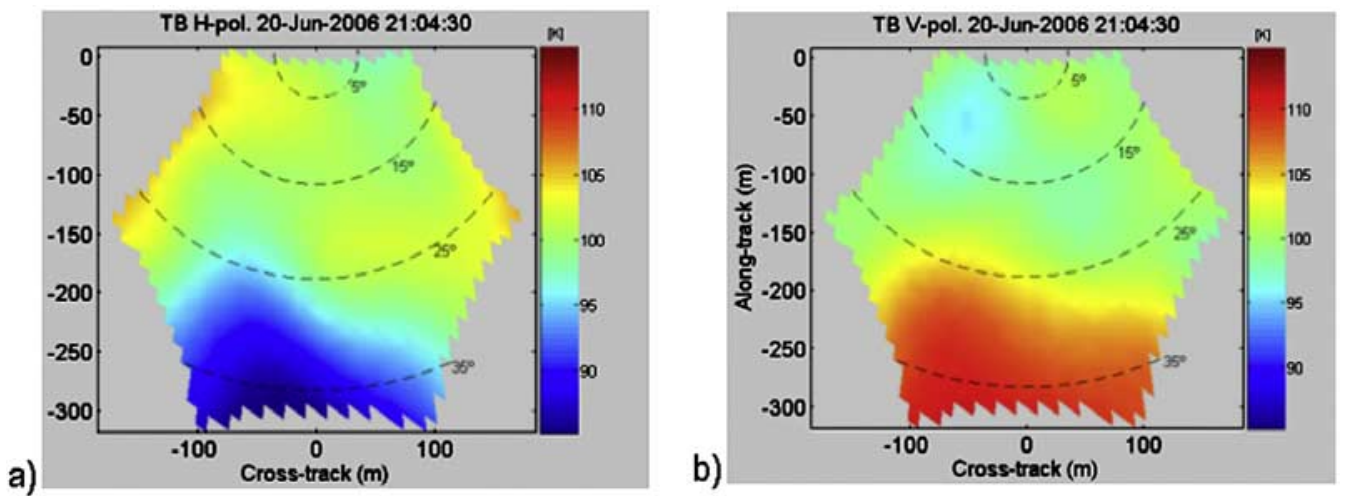

Figure 16. SMOSillo retrieved brightness temperatures over Lake Lohja at (a) horizontal and (b) vertical polarizations. Constant incidence angle contours from $5^{\circ}$ to $35^{\circ}$ shown as dashed lines.

tive snap-shots) in which a 2 psu step has been assumed over a $10^{\circ}$ latitude range: (a) the retrieved and the original SSS fields, (b) the SSS error histogram, and (c) an histogram of the salinity error variance $\left(\sigma_{S S S}^{2}\right)$ as a function of the number of observations, which decreases with increasing $N_{o b s}$, and flattens above $N_{o b s}>$ 30-40 [Talone et al., 2007]. Note that in Figure 15a the salinity retrieval errors increase with the distance to the satellite ground-track, and errors are larger in the top and bottom regions due to the smaller number if snap-shots that imaged those regions.

\subsection{Experimental Studies}

[52] Sea surface salinity has been successfully retrieved using multiangular radiometric data acquired with a real aperture radiometer during WISE 2000 and 2001 field experiments [Gabarró et al., 2004b; Camps et al., 2004a].

[53] In an attempt to apply for the first time sea surface salinity retrieval algorithms with two-dimensional synthetic aperture brightness temperatures images, equation (2) has been applied with a data set acquired on 20 June 2006 with the SMOSillo aboard the TKK (Helsinki University of Technology) Skyvan [Duffo et al., 2007; First images from airborne version of SMOS, 2007] flying over lake Lohja, West of Helsinki [Rautiainen et al., 2007]. The data processing techniques for this small demonstrator are the same as those that will be used in the MIRAS flight instrument aboard SMOS, from raw visibility samples (cross-correlation products) to calibrated visibilities [Corbella et al., 2005] and the image reconstruction algorithm applied is a simple inverse fast Fourier transform over the hexagonal grid of spatial frequencies [Camps et al., 1997], plus antenna pattern and obliquity factor compensation.

[54] Figure 16 show a sample snap-shot of the brightness temperatures at (a) horizontal and (b) vertical polar- izations. Due to the axes definition in SMOSillo, the upper part of the images corresponds to the incidence angles closest to nadir, and the lower part to the largest ones, as opposed to Figure $1 \mathrm{~b}$.

[55] Although the brightness temperature images should be symmetrical, a distortion occurs in the lower left part (larger incidence angles), which may be due to uncorrected antenna pattern errors and spill over of alias images in the alias-free field-of-view of the instrument due to the antenna spacing and the limited angular resolution of the instrument.

[56] To avoid polarization mixing effects originated by the geometrical rotation, only data points corresponding

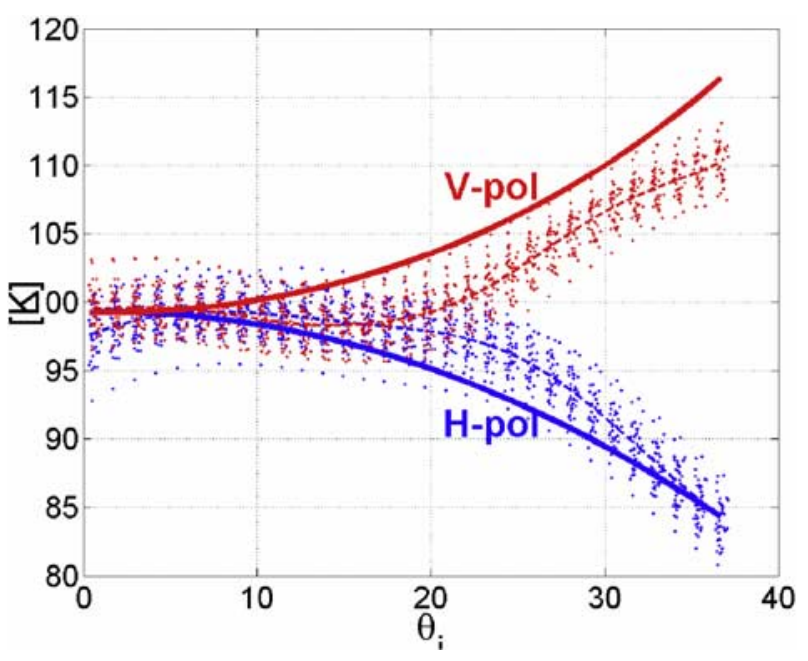

Figure 17. Dots: brightness temperature data points over a line of cross-track $=0 \mathrm{~m}$ (no geometric rotation). Dashed lines: average values of the data points. Solid line: brightness temperature modeled with the retrieved parameters. 
to cuts of consecutive snap-shots over the cross-track direction $=0 \mathrm{~m}$ are presented in Figure 17 as dots. Dashed lines correspond to the average values at each incidence angle. It must be pointed out that the data points shown have been corrected with the internal calibration methods (uncorrelated/correlated noise injection) to compensate for offsets, phase and amplitude errors between receiving elements, a simple atmospheric and cosmic background correction has been applied: $R_{p}\left(\theta_{i}\right)\left[2.7+1.8 / \cos \left(\theta_{i}\right)\right]$, where $R_{p}\left(\theta_{i}\right)$ is the Fresnel reflection coefficient at $p$-polarization (amplitude squared), $2.7 \mathrm{~K}$ is the cosmic background, $1.8 \mathrm{~K}$ is the downwelling atmospheric temperature (clear atmosphere) and $\theta_{i}$ is the incidence angle, and the effect of the finite antenna pattern beamwidth has been accounted for. It must be pointed out that the small brightness temperature increase at lower incidence angles may be due to the reflection of the "hot" aircraft over the sea collected at nadir by the radiometer synthetic beam. (Thomann [1976] reported an increase in the nadir antenna temperature of about $3 \mathrm{~K}$ for a $30 \mathrm{~m}$ wingspan plane flying at $244 \mathrm{~m}$ height for an antenna of $15^{\circ}$ beamwidth. In the SMOSillo case the TKK Skyvan height was $400 \mathrm{~m}$, and the synthetic beamwidth was $11.8^{\circ}$.)

[57] After these corrections, the minimization of equation (2) in terms of the first Stokes parameter with no restrictions on $S S T$ and $U_{10}\left(\sigma_{S S T} \rightarrow \infty, \sigma_{U_{10}} \rightarrow \infty\right)$, leads to $S S S_{\text {retrieved }}$ between 0.30 and 0.53 psu depending on the initial guess 0 or $38 \mathrm{psu}$, respectively, in good agreement with the expected salinity (fresh water). The retrieved values of $S S T_{\text {retrieved }}=4.2^{\circ} \mathrm{C}$ and the effective wind speed $U_{10}$ eff retrieved $=8.4 \mathrm{~m} / \mathrm{s}$ (3-parameter retrieval) exhibit a larger error, but are not too far apart from the measurements reported by the Lohja Weather Station for that date: $S S T=8^{\circ} \mathrm{C}$ and average $U_{10}=0.6 \mathrm{~m} / \mathrm{s}\left(U_{10, \max }=\right.$ $6.3 \mathrm{~m} / \mathrm{s})$, although it is worth to note that the sensitivity of $T_{B}$ to $S S T$ is weak, and large errors can be accepted, and that the effective wind speed retrieved is not directly correlated to the wind speed, but it accounts for other sea surface roughness effects.

[58] Further studies will be devoted to improve the calibration and image reconstruction capabilities of this airborne demonstrator so as to improve the quality of the geophysical parameters retrieved.

\section{Conclusions}

[59] This work has summarized the main effects that have to be taken into account to model the sea surface emission at L-band, and the existing approaches to perform the sea surface salinity retrieval from multiangular radiometric measurements. In this context, the activities carried out in the past years by the Universitat
Politècnica de Catalunya (UPC) in collaboration with the Institut de Ciències del Mar (ICM - CSIC) have been described: the seawater dielectric constant measurements, with the associated uncertainties, the study of the impact on the brightness temperature of sea state, the effect of wave development, swell, currents, rain, and oil spills, and the development of iterative SSS retrieval algorithms using multiangular radiometric data tailored to the SMOS imaging configurations. Simulation results have been presented to assess the performances that could be achieved in different scenarios, as well as a salinity retrieval application using data acquired by the SMOSillo aboard the TKK Skyvan over Lake Lohja, West of Helsinki.

[60] Despite the advances in the sea surface emission modeling both from a numerical and from a experimental point of view, and in the definition of the sea surface salinity retrieval algorithms, a number of effects are not yet well know or understood and will require further research:

[61] 1. The uncertainties in the dielectric constant model, which lead to errors in the SSS estimates.

[62] 2. The uncertainties in the sea state description (sea surface spectrum and parameters) and the best numerical model. For $U_{10}<7-8 \mathrm{~m} / \mathrm{s}$ and $\theta_{i}<20^{\circ}$, the SSA model seems to be in better agreement than the TSM which overestimates the $T_{B}$ sensitivity, while for $\theta_{i}>20^{\circ}$ and H-polarization the TSM seems to perform better. For $U_{10}>8 \mathrm{~m} / \mathrm{s}$ and at all incidences, both models strongly underestimate the roughness impact at moderate to high winds [Reul et al., 2007].

[63] 3. The large scattering that appears in the experimental data hampers the improvement of numerical models, which may be ultimately due to the intrinsec geophysical variability of the magnitude under measurement.

[64] 4. The definition of the cost function (equation (2)) is still object of discussion: whether or not use restrictions in salinity and with which variance, and weather or not the weight in the first term $\left(1 / N_{\text {obs term }}\right)$ must be applied.

[65] 5. The optimum use of the available auxiliary data (maximum depth of salinity data from ARGO drifters, for example) needed to calibrate both the brightness temperature bias that appears after the image reconstruction process (level $1 \mathrm{C}$ ), and the salinity bias that appears after the salinity retrieval process (level 2) due to inaccuracies in the dielectric constant model and the description of the sea state impact of the brightness temperature.

[66] Future research lines include the systematic exploitation of the L2-prototype processor in conjunction with latest version of the SEPS to analyze the SSS retrieval error budget for SMOS, to evaluate the best SSS retrieval configuration for SMOS and test future improvements over current algorithms. 
[67] Acknowledgments. This work has been supported by ESA Projects ESA, ESTEC contract 141888/00/NL/DC, CCN-1 and CCN2, ESA contract 18176/04/NL/CB, and Spanish Research projects and EU FEDER CICYT TIC 99-1050-C0301, TIC2002-04451-C02-01, TEC2005-06863-C02-01, PNE009/2001-C-02, ESP2002-11648-E, ESP2004-00671, and ESP2005-06823-C05.

\section{References}

Ammar, A., S. Labroue, E. Obligis, C. Mejia, S. Thiria, and M. Crepon (2006), Sea surface salinity retrieval throughout a SMOS half-orbit using neural networks, paper presented at IEEE MicroRad, San Juan, Puerto Rico.

Blanch, S., and A. Aguasca (2004), Seawater dielectric permittivity model from measurements at L-band, paper presented at International Geoscience and Remote Sensing Symposium IGARSS 2004, 20-24 Sept.

Blume, H. J. C., H. Huhnerfuss, and W. Alpers (1983), Variation of the microwave brightness temperature of sea surfaces covered with mineral and monomolecular oil films, IEEE Trans. Geosci. Remote Sens., 21(3), 295-300.

Boutin, J., P. Waldteufel, N. Martin, G. Caudal, and E. Dinnat (2004), Surface salinity retrieved from SMOS measurements over global ocean: Imprecisions due to sea surface roughness and temperature uncertainties, J. Atmos. Oceanic Technol., 21(1), 1432-1447.

Burgess, T. M., and R. Webster (1980), Optimal interpolation and isarithmic mapping of soil properties; I The semi-variogram and punctual kriging, Eur. J. Soil Sci., 31(2), 315.

Camps, A., J. Bará, I. Corbella, and F. Torres (1997), The processing of hexagonally sampled signals with standard rectangular techniques: Application to 2D large aperture synthesis interferometric radiometers, IEEE Trans. Geosci. Remote Sens., 35(1), 183-190.

Camps, A., et al. (2001), Wind and Salinity Experiment 2000 (WISE 2000): Scientific analysis report, contract 14188/00/ NL/DC, ESTEC, Noordwijk, Netherlands, Aug.

Camps, A., et al. (2003), L-band sea surface emissivity: Preliminary results of the WISE-2000 campaign and its application to salinity retrieval in the SMOS mission, Radio Sci., 38(4), 8071, doi:10.1029/2002RS002629.

Camps, A., et al. (2004a), The WISE 2000 and 2001 campaigns in support of the SMOS mission: Sea surface L-band brightness temperature observations and their application to multiangular salinity retrieval, IEEE Trans. Geosci. Remote Sens., 42(4), 804-823.

Camps, A., M. Vall-llossera, J. Miranda (2004b), Sea surface brightness temperature at L-band: Impact of surface currents, paper presented at IGARSS 2004, Anchorage, Alaska, $20-$ 24 Sept.

Camps, A., M. Vall-1lossera, L. Batres, F. Torres, N. Duffo, and I. Corbella (2005a), Retrieving sea surface salinity with multiangular L-band brightness temperatures: Improvement by spatio-temporal averaging, Radio Sci., 40, RS2003, doi:10.1029/2004RS003040.
Camps, A. et al. (2005b), The emissivity of foam-covered water surface at L-band: Theoretical modeling and experimental results from the Frog 2003 Field Experiment, IEEE Trans. Geosci. Remote Sens., 43(5), 925-937.

Camps, A., M. Vall-1lossera, N. Duffo, F. Torres, and I. Corbella $(2005 c)$, Performance of sea surface salinity and soil moisture retrieval algorithms with different ancillary data sets in 2D L-band aperture synthesis interferometric radiometers, IEEE Trans. Geosci. Remote Sens., 43(5), 1189-1200.

Camps, A., M. Vall-llossera, I. Corbella, N. Duffo, and F. Torres (2006), Improved image reconstruction algorithms for aperture synthesis radiometers, paper presented at Internacional Geoscience and Remote Sensing Symposium IGARSS 2006, Denver, Colo., 31 July to 4 Aug.

Claassen, J. P., and A. K. Fung (1974), The recovery of polarized apparent temperature distributions of flat scenes from antenna temperature measurements, IEEE Trans. Antennas Propag., $22,433-442$.

Corbella, I., F. Torres, A. Camps, A. Colliander, M. MartínNeira, S. Ribó, K. Rautiainen, N. Duffo, and M. Vall-llossera (2005), MIRAS end-to-end calibration: Application to SMOS L1 processor, IEEE Trans. Geosci. Remote Sens., 43(5), 1126-1134.

Cox, C. S., and W. H. Munk (1954), Statistics of the sea surface derived from Sun glitter, J. Mar. Res., 13, 198-227.

Craeye, C., P. W. Sobieski, and L. F. Bliven (1997), Scattering by artificial wind and rain roughened water surfaces at oblique incidences, Int. J. Remote Sens., 18(10), 2241-2246.

Dinnat, E. P., and M. Drinkwater (2004), Optimizing the active/ passive synergy in the frame of the sea surface salinity retrieval from microwave measurements at L-band, paper presented at SMOS-Aquarius Joint Science Workshop, Miami, $20-22$ April.

Dinnat, E. P., J. Boutin, G. Caudal, and J. Etcheto (2003), Issues concerning the sea emissivity modeling at $\mathrm{L}$ band for retrieving surface salinity, Radio Sci., 38(4), 8060, doi:10.1029/2002RS002637.

Dobson, F., W. Perrie, and B. Toulany (1989), On the deepwater fetch laws for wind-generated surface gravity waves, Atmos. Ocean, 27(1), 210-236.

Donelan, M. A., J. Hamilton, and W. H. Hui (1985), Directional spectra of wind generated waves, Philos. Trans. R. Soc. London, Ser. A, 315, 509-562.

Duffo, N., F. Torres, I. Corbella, V. González, S. Blanch, A. Camps, M. Vall-llossera, J. L. Álvarez, S. Ribó, and M. Martin-Neira (2007), Some results of the MIRAS-SMOS demonstrator campaigns, paper presented at Internacional Geoscience and Remote Sensing Symposium IGARSS 2007, Barcelona, Spain, 23 -27 July.

Durden, S. L., and J. F. Vesecky (1985), A physical radar crosssection model for a wind-driven sea with swell, IEEE $J$. Oceanic Eng., 10(4), 445-451.

Elfouhaily, T., B. Chapron, K. Katsaros, and D. Vandermark (1997), A unified directional spectrum for long and short 
wind-driven waves, J. Geophys. Res., 102(C7), 15,78115,796 .

Ellison, W., A. Balana, G. Delbos, K. Lamkaouchi, L. Eymard, C. Guillou, and C. Prigent (1998), New permittivity measurements of seawater, Radio Sci., 33(3), 639-648.

Etcheto, J. E., P. Dinnat, J. Boutin, A. Camps, J. Miller, S. Contardo, J. Wesson, J. Font, and D. G. Long (2004), Wind speed effect on L-band brightness temperature inferred from EuroSTARRS and WISE 2001 field experiments, IEEE Trans. Geosci. Remote Sens., 42(10), 2206-2213.

First images from airborne version of SMOS (2007), (Available at http://www.esa.int/esaLP/SEMJVPOFHTE_index_0.html and http://www.esa.int/esaLP/SEMSYFNZ̄CIE_index 0.html)

Font, J., G. S. E. Lagerloef, D. M. Le Vine, A. Camps, and O. Z. Zanife (2004), The determination of surface salinity with the European SMOS space mission, IEEE Trans. Geosci. Remote Sens., 42(10), 2196-2205.

Gabarró, C., J. Font, A. Camps, M. Vall-llossera, and A. Julià (2004a), A new empirical model of sea surface microwave emissivity for salinity remote sensing, Geophys. Res. Lett., 31, L01309, doi:10.1029/2003GL018964.

Gabarró, C., M. Vall-llossera, J. Font, and A. Camps (2004b), Determination of sea surface salinity and wind speed by Lband microwave radiometry from a fixed platform, Int. J. Remote Sens., 25(1), 111-128.

Huang, N. E., D. T. Chen, C. C. Tung, and J. R. Smith (1972), Interactions between steady non-uniform currents and gravity waves with applications for current measurements, J. Phys. Oceanogr., 2, 420-431.

Irisov, V. G. (1997), Small-slope expansion for thermal and reflected radiation from a rough surface, Waves Random Media, 7, 1-10.

Kerr, Y. H., P. Waldteufel, J. P. Wigneron, J. Martinuzzi, J. Font, and M. Berger (2001), Soil moisture retrieval from space: The Soil Moisture and Ocean Salinity (SMOS) mission, IEEE Trans. Geosci. Remote Sens., 39(8), 1729-1735.

Klein, L. A., and C. T. Swift (1977), An improved model for the dielectric constant of seawater at microwave frequencies, IEEE J. Oceanic Eng., 2(1), 104-111.

Koblinsky, C. J., P. Hildebrand, D. M. Le Vine, F. Pellerano, Y. Chao, W. J. Wilson, S. Yueh, and G. S. E. Lagerloef(2003), Sea surface salinity from space: Science goals and measurement approach, Radio Sci., 38(4), 8064, doi:10.1029/ 2001 RS002584.

Kudryavtsev, V. N., V. K. Makin, and B. Chapron (1999), Coupled sea surface-atmosphere model: 2. Spectrum of short wind waves, J. Geophys. Res., 104(C4), 7625-7639.

Lagerloef, G. S. E. (2000), Recent progress toward satellite measurements of the global sea surface salinity field, in Satellites, Oceanography, and Society, edited by D. Halpern, pp. 309-319, Elsevier, Amsterdam, Netherlands.

Le Vine, D. M., and S. Abraham (2002), The effect of the ionosphere on remote sensing of the sea surface salinity from space: Absorption and emission at L-band, IEEE Trans. Geosci. Remote Sens., 40(4), 771-782.

Martín-Neira, M., S. Ribó, and A. J. Martín-Polegre (2002), Polarimetric mode of MIRAS, IEEE Trans. Geosci. Remote Sens., 40(8), 1755-1768.

Mätzler, C. (2006), Thermal Microwave Radiation: Applications for Remote Sensing, Inst. of Electr. Eng., London, UK.

Miranda, J., M. Vall-llossera, R. Villarino, and A. Camps (2003a), Sea state and rain effects in the sea surface emissivity at L-Band, paper presented at First Results Workshop on WISE/LOSAC/EuroSTARSS Campaigns, ESA, France, March.

Miranda, J. J., M. Vall-llossera, A. Camps, N. Duffo, I. Corbella, and J. Etcheto (2003b), Sea state effect on the sea surface emissivity at L-band, IEEE Trans. Geosci. Remote Sens., 41(10), 2307-2315.

Monahan, E. C., and M. Lu (1990), Acoustically relevant bubble assemblages and their dependence on metereological parameters, IEEE J. Oceanic Eng., 15, 340-349.

Monahan, E. C., and I.G. O’Muircheartaigh (1986), Whitecaps and the passive remote sensing of the ocean surface, Int. J. Remote Sens., 7(5), 627-642.

Monahan, E. C., and D. K. Wolf (1989), Comments on variations of whitecap coverage with wind stress and water temperature, J. Phys. Oceanogr., 19, 706-709.

Rautiainen, K., J. Kainulainen, T. Auer, S. Tauriainen, and M. Hallikainen (2007), Helsinki University of Technology Synthetic Aperture Radiometer - HUT-2D, paper presented at Internacional Geoscience and Remote Sensing Symposium IGARSS 2007, Barcelona, Spain, 23-27 July.

Reul, N., and B. Chapron (2001), SMOS-salinity data processing study: Improvements in emissivity models (WP 1100 report), contract 15165/01/NL/SF, ESA, Noordwijk, Netherlands, Oct.

Reul, N., and B. Chapron (2003), A simple algorithm for the sea surface salinity retrieval from L-band radiometric measurements at nadir, paper presented at SMOS Workshop.

Reul, N., et al. (2006), Synergetic aspects and auxiliary data concepts for sea surface salinity measurements from space, Final Rep. 18176/04/NL/CB, ESA ESTEC, Noordwijk, Netherlands, Jan. (Available at ftp://ftp.estec.esa.nl/pub/vr/ SMO/Salinity_Synergy_18176_FR.pdf)

Reul, N., et al. (2007), CoSMOS-OS campaign scientific data analysis results, paper presented at CoSMOS Final Meeting, ESTEC, 31 May.

Sabia, R., A. Camps, M. Vall-llossera, and N. Reul (2006), Impact on sea surface salinity retrieval of different auxiliary data within the SMOS mission, IEEE Trans. Geosci. Remote Sens., 44(10), 2769-2778.

Sabia, R., M. Caparrini, A. Camps, and G. Ruffini (2007), Potential synergetic use of GNSS-R signals to improve the sea-state correction in the sea surface salinity estimation: Application to the SMOS mission, IEEE Trans. Geosci. Remote Sens., 45(7, Part 1), 2088-2097.

Skou, N., and D. Hoofman-Bang (2005), L-band radiometers measuring salinity from space: Atmospheric propagation ef- 
fects, IEEE Trans. Geosci. Remote Sens., 43(10), 22102217.

SMOS ATBD OS (2005), SMOS SSS L2 algorithm theoretical baseline document, SO-L2-SSS-ACR-001, Rev. 4, 7 Nov.

Swift, C. T., and R. E. McIntosh (1983), Considerations for microwave remote sensing of ocean surface salinity, IEEE Trans. Geosci. Remote Sens., 21(4), 480-491.

Talone, M., A. Camps, J. Font, and R. Sabia (2007), Towards a coherent sea surface salinity product from SMOS radiometric measurements and ARGO buoys, paper presented at Internacional Geoscience and Remote Sensing Symposium IGARSS 2007, Barcelona, Spain, 23-27 July.

Thomann, G. (1976), Experimental results of the remote sensing of sea-surface salinity at $21-\mathrm{cm}$ wavelength, IEEE Trans. Geosci. Electron., 14(3), 198-214.

Vall-llossera, M., J. Miranda, A. Camps, and R. Villarino (2003), Sea surface emissivity modelling at L-band: An inter-comparison study, in Proceedings of EuroSTARRS, WISE and LOSAC First Results Workshop, ESA Spec. Publ., $S P-525,143-153$.

Waldteufel, P., N. Floury, E. P. Dinnat, and G. Caudal (2004), Ionospheric effects for L-band 2-D interferometric radiometry, IEEE Trans. Geosci. Remote Sens., 42(1), 105-118.
Webster, W. J., Jr., et al. (1976), Spectral characteristics of the microwave emission from a wind-driven foam-covered sea, J. Geophys. Res., 81, 3095-3099.

Wilson, W. J., S. H. Yueh, S. J. Dinardo, and F. K. Li (2004), High-stability L-band radiometer measurements of saltwater, IEEE Trans. Geosci. Remote Sens., 42(9), 1829-1835.

Yueh, S. H. (2000), Estimates of Faraday rotation with passive microwave polarimetry for microwave remote sensing of Earth surfaces, IEEE Trans, Geosci. Remote Sens., 38(5, Part 2), 2434-2438.

A. Aguasca, S. Blanch, A. Camps, I. Corbella, N. Duffo, J. Miranda, R. Sabia, F. Torres, and M. Vall-llossera, Universitat Politècnica de Catalunya, Campus Nord, D4, 08034 Barcelona, Spain. (camps@tsc.upc.edu)

L. Enrique, ICFO - Institut de Ciències Fotòniques, Avda. Canal Olímpic, s/n, 08860 Castelldefels, Spain.

J. Font, C. Gabarró, and M. Talone, Institut de Ciències del Mar-CSIC, Passeig Marítim, 37-49, 08003 Barcelona, Spain.

R. Villarino, Universitat Autònoma de Barcelona, ETSE QC-2003, 08193 Cerdanyola del Vallès, Spain. 